\title{
Pervasive refusal syndrome as part of the refusal-withdrawal- regression spectrum: critical review of the literature illustrated by a case report
}

\author{
Tine Jaspers · G. M. J. Hanssen • \\ Judith A. van der Valk · Johann H. Hanekom • \\ Gijs Th. J. van Well · Jan N. M. Schieveld
}

Received: 6 June 2008/Accepted: 29 April 2009/Published online: 21 May 2009

(c) The Author(s) 2009. This article is published with open access at Springerlink.com

\begin{abstract}
Pervasive refusal syndrome (PRS) is a rare child psychiatric disorder characterized by pervasive refusal, active/angry resistance to help and social withdrawal leading to an endangered state. Little has been written about PRS. A literature search yielded only 15 relevant articles, all published between 1991 and 2006. This article presents a critical review of the published literature, illustrated by a case report of an 11-year-old girl. PRS most often affects girls $(75 \%)$. The mean age of the known population is 10.5 years. A premorbid high-achieving, perfectionist, conscientious personality seems to play an important role in the aetiology of PRS, as can a psychiatric history of parents or child and environmental stressors.
\end{abstract}

G. M. J. Hanssen and J. A. van der Valk contributed equally to this paper.

T. Jaspers · J. N. M. Schieveld

Department of Psychiatry and Neuropsychology,

European Graduate School of Neuroscience,

Maastricht University Medical Centre, PO Box 5800,

6202 AZ Maastricht, The Netherlands

T. Jaspers $(\varangle)$

Department of Child and Adolescent Psychiatry,

University Hospital Gasthuisberg, Herestraat 49,

3000 Louvain, Belgium

e-mail: tine.jaspers@skynet.be

G. M. J. Hanssen · J. A. van der Valk

Faculty of Health, Medicine and Life Sciences,

Maastricht University, Maastricht, The Netherlands

J. H. Hanekom

Department of Paediatrics, Laurentius Hospital Roermond, PO Box 920, 6040 AX Roermond, The Netherlands

G. Th. J. van Well

Department of Paediatrics, Maastricht University Medical

Centre, PO Box 5800, 6202 AZ Maastricht, The Netherlands
PRS shows a symptom overlap with many other psychiatric disorders. However, none of the current DSM diagnoses can account for the full range of symptoms seen in PRS, and the active/angry resistance can be considered as the main distinguishing feature. Treatment should be multidisciplinary and characterized by patience, gentle encouragement and tender loving care. Hospitalization, ideally in a child and adolescent psychiatric unit, is almost always required. Although the recovery process is painfully slow (average duration of therapy 12.8 months), most children recover fully (complete recovery in $67 \%$ of known cases). In our opinion, it is important to increase knowledge of PRS, not only because of its disabling, potential lifethreatening character, but also because there is hope for recovery through suitable treatment. We therefore propose an incorporation of PRS into the DSM and ICD classifications. However, an adaptation of the current diagnostic criteria is needed. We also consider PRS closely related to regression, which is why we introduce a new concept: "the refusal-withdrawal-regression spectrum".

Keywords Pervasive refusal syndrome - Refusal . Withdrawal $\cdot$ Regression $\cdot$ Child psychiatry

\section{Introduction}

Pervasive refusal syndrome (PRS) is a rare and severe child psychiatric disorder defined by clear food refusal and weight loss, social withdrawal, partial or complete refusal in two or more domains (mobilization/speech/attention to self-care) and an active/angry resistance to acts of help or encouragement [24].

The concept of PRS was first introduced by Lask et al. [13]. A literature search on PRS yielded only 15 articles 
(vide infra); two supplementary articles were found on the subject through the feedback of colleagues. We present a critical review of the existing literature, illustrated by a case report. Based on a comparison of our clinical experience with the existing literature, we suggest adapting the current diagnostic criteria. We also introduce the concept of the refusal-withdrawal-regression spectrum, of which PRS is a part.

It is important, in our opinion, to foster greater insight into PRS, not only due to its particularly incapacitating character, but also because there is hope for recovery through suitable treatment. We hope this article will contribute to an increased awareness of its existence.

\section{Case report}

Kate, ${ }^{1}$ a highly intelligent, 11-year-old Caucasian prepubertal female, was referred to our academic medical psychiatric unit for children by a local paediatrician for a second opinion. She had a 6-month history of increasing unexplainable somatic complaints, starting with acute fatigue, a sore throat and a headache. The symptoms developed into an inability to walk, nausea, eating problems, joint pains, diplopia, dizziness and urinary frequency, resulting in progressive social withdrawal. Kate stayed in all day, did not go to school and became disinterested. Medical history was unremarkable, while psychiatric history revealed perfectionist and overachieving personality features and a history of tantrums at the age of 7 .

The acute onset suggested a stressful event prior to the start of her complaints. Parent and child only described a troubled relationship with one particular teacher, who taught her for 2.5 consecutive years, shouted at her and, at times, openly ignored her. Changing school did not relieve the symptoms but was associated with a deterioration. Physical or sexual abuse was explicitly denied. The family history was irrelevant, although an enmeshed mother-child relationship was noted.

During the admission, which was primarily diagnostically focused and further characterized by an attitude of gentle encouragement and tender loving care, Kate's condition deteriorated. Her immobility increased to the point that she stayed in bed all day and could only crawl. She refused solid food, resulting in a weight loss of $3 \mathrm{~kg}$. Kate increasingly complained about headaches and feeling cold. The situation eventually led to her lying in bed with a coat on and covered with approximately ten folded bed sheets. She yawned every $30 \mathrm{~s}$ and crawled to the toilet every couple of minutes. This behaviour made a very forced and

\footnotetext{
1 To ensure anonymity, we selected a fictitious name for the index patient.
}

theatrical impression. Her complaints seemed to fluctuate, particularly worsening when parents or medical/nursery staff were present. From informal remarks made by her room-mates and their visitors, we learned that Kate could walk and talk normally when we or her parents were not present.

Whereas Kate underwent the medical investigations passively, she actively refused to cooperate with any of the psychological or psychiatric investigations and any attempts made by others to stimulate her. She constantly asked to be left alone when someone entered the room. If her request to leave was not directly obeyed, she turned away, began to whine and no longer responded to questions, impeding any further attempts at conversation. When we gently tried to motivate her, she became aggressive.

Despite many somatic multidisciplinary investigations, no organic cause of her complaints could be traced. Laboratory investigations of blood, urine and faeces showed no abnormalities. There were no serological markers associated with beta-haemolytic streptococcus group A infection (GABHS), ruling out PANDAS (paediatric auto-immune neuropsychiatric disorders associated with streptococcal infections). An MRI of the brain showed no abnormalities. A provocation test to exclude a central hypothermia syndrome showed no drop in core body temperature, thereby ruling out hypothermia.

Given the severity, deteriorating and disabling character of her disorder, with a GAF (global assessment of functioning) score of 21-30, we were forced to transfer Kate to a child psychiatric hospital for what we expected might become a long-term inpatient rehabilitation programme.

However, after 3 months of patient and gentle rehabilitation, a spontaneous and nearly complete recovery occurred. There remained some fatigue, but it soon disappeared. Kate returned to high school on a full-time basis and outpatient follow-up was discontinued by both her and her parents.

\section{Discussion}

\section{Literature search}

Pervasive refusal syndrome was first brought to our attention by a Dutch publication [25]. An extensive literature search (Cochrane, Embase, PsychInfo, PubMed), conducted in April 2008, yielded only 20 articles for the search term pervasive refusal syndrome. Three of the articles were irrelevant because they dealt with entirely different topics, and two described eating disorders [5, 10] with PRS mentioned only marginally. The remaining 15 articles [2-4, 7-9, 11, 13, 17-19, 23, 24, 26, 27], published between 1991 and 2006, described only 23 distinct cases of 
PRS. A supplementary article [12], brought to our attention by a colleague, mentioned 20 more cases of PRS. Owing to a lack of detail, however, these cases could not be incorporated into our study population $(n=24)$. Population characteristics of the 24 patients are presented in Table 1 .

The search on PsychInfo also yielded three textbooks on eating disorders $[14,16,22]$ in which PRS is mentioned.

Remarkably, the two main textbooks on child and adolescent psychiatry $[15,20]$ contain no information at all about PRS. The DSM-IV [1] and ICD-10 [29] do not classify PRS.

\section{Epidemiology}

Pervasive refusal syndrome is most often seen in girls between the ages of 7 and 15. As illustrated in Table 1, $75 \%$ of the 24 patients were female and the mean age of the population was 10.5 years. Kate perfectly fits this profile. Occurrence of PRS in adults has not been reported. The incidence of the disorder is unknown [11].

\section{Aetiology}

In the first article published on PRS [13], there seemed to be an association between PRS and sexual abuse. Later articles denied such an association. Reviewing the literature, however, sexual abuse was reported in $21 \%$ of the 24 cases (see Table 2), which is not an insignificant percentage. Trauma, in general, seems to be an important aetiological factor, since PRS is also often seen in refugees and witnesses to violence (see Table 2).

Nunn and Thompson [18] introduced the concept of learned helplessness and hopelessness. They proposed that the symptoms seen in children with PRS emerge from the perceived uncontrollability of their future and the

Table 1 Population characteristics PRS $(n=24)^{\mathrm{a}}$, 1991-2006

\begin{tabular}{ll}
\hline Characteristics & Frequency (total $n=24)$ \\
\hline Age (mean \pm SD) & $10.5 \pm 2.6$ \\
Male & $6(25 \%)$ \\
$n$ & $9.0 \pm 3.3$ \\
Age (mean \pm SD) & \\
Female & $18(75 \%)$ \\
$n$ & $10.9 \pm 2.2$ \\
Age (mean \pm SD) & $15(63 \%)$ \\
Ethnicity & $5(21 \%)$ \\
Not reported & $4(17 \%)$ \\
Asian & \\
White & \\
\hline
\end{tabular}

${ }^{a}$ Twenty-three patients from the literature search +1 patient from the Dutch article [25]
Table 2 Aetiologic factors of PRS $(n=24)^{\mathrm{a}}$, 1991-2006

\begin{tabular}{|c|c|}
\hline Aetiologic factors & $\begin{array}{l}\text { Frequency } \\
\text { (total } n=24 \text { ) }\end{array}$ \\
\hline \multicolumn{2}{|l|}{ Premorbid personality } \\
\hline High-achieving, perfectionist, conscientious & $11(46 \%)$ \\
\hline \multicolumn{2}{|l|}{ Psychiatric history of child } \\
\hline Positive & $9(38 \%)$ \\
\hline Negative & $11(46 \%)$ \\
\hline Not reported & $4(17 \%)$ \\
\hline \multicolumn{2}{|l|}{ Psychiatric history of parents } \\
\hline Positive & $8(33 \%)$ \\
\hline Negative & $7(29 \%)$ \\
\hline Not reported & $9(38 \%)$ \\
\hline \multicolumn{2}{|c|}{ Enmeshed mother-child relationship/over-involvement } \\
\hline Positive & $15(63 \%)$ \\
\hline Not reported & $9(38 \%)$ \\
\hline \multicolumn{2}{|l|}{ Known stressors } \\
\hline Witness to violence & $7(29 \%)$ \\
\hline Refugee & $6(25 \%)$ \\
\hline Sexual abuse & $5(21 \%)$ \\
\hline Marital/parental problems & $3(13 \%)$ \\
\hline Relocation & $3(13 \%)$ \\
\hline Family loss & $2(8 \%)$ \\
\hline Change of school & $1(4 \%)$ \\
\hline Emotional abuse & $1(4 \%)$ \\
\hline Bullying & $1(4 \%)$ \\
\hline No known traumatic event & $5(21 \%)$ \\
\hline \multicolumn{2}{|l|}{ Precipitating events } \\
\hline Infection/viral infection & $9(38 \%)$ \\
\hline Injury & $2(8 \%)$ \\
\hline Post-surgery & $1(4 \%)$ \\
\hline Major somatic history & $1(4 \%)$ \\
\hline Asylum rejection & $1(4 \%)$ \\
\hline Unknown & $10(42 \%)$ \\
\hline
\end{tabular}

${ }^{a}$ Twenty-three patients from the literature search +1 patient from the Dutch article [25]

expectation that responses are futile. The helplessness and hopelessness can transfer from parents to children and from children to parents as they watch one another struggling with uncontrollable events [18].

Other theories concerning the aetiology of PRS have been postulated, such as the psychodynamic theory of lethal mothering [4] and a possible neurobiological contribution of the insula [24]. Viral infections are often seen as precipitating factors (see Table 2).

Von Folsach and Montgomery [27] proposed four important aetiologic factors: (1) a premorbid personality, (2) a history of child psychiatric problems, (3) parental psychiatric problems and (4) precipitating stressful events. Reviewing the literature, these four factors indeed seem to 
play an important role in the aetiology (see Table 2). Children with PRS are usually described as perfectionist, conscientious and high achievers. When such children are faced with stressful events that they feel they cannot control, they enter into a state of learned helplessness. Previous child psychiatric problems may indicate a vulnerability to develop PRS when faced with stressful events, and parental psychiatric problems may affect the parents' ability to support and protect their children. Enmeshed mother-child relationships are often seen $(63 \%)$, but it is unclear whether they are primary or secondary to the child becoming ill.

The aetiology of PRS in our case report remains unclear. Returning to Kate, the troubled relationship with the teacher can be considered a potential precipitating event, or a chronic stress factor, since he taught her for 2.5 consecutive years. Changing school only worsened the symptoms. This change, however, can be considered a supplementary stress factor. Physical or sexual abuse was explicitly denied. A precipitating viral infection could have been the trigger, since Kate's complaints started with acute fatigue, a sore throat and a headache.

Kate also seems to fulfil criteria 1 and 2 of Von Folsach and Montgomery [27]. She was known as a perfectionist and high-achieving girl and had a history of an episode of behavioural disturbances. No parental psychiatric problems were present. During the period of admission to our hospital, we did notice an enmeshed mother-child relationship, as well as helplessness and hopelessness in both mother and child, but these seemed to be secondary effects.

\section{Psychopathological consideration}

Refusal, which is considered one of the core symptoms of PRS, is defined as a state in which one is unwilling to do something [28]. Withdrawal, another core symptom of PRS, can be defined as a retreat from external reality [6] or a state of ceasing to participate in an activity or to be a member of a team or organization [28]. In clinical psychiatry, a third and related psychopathological state exists: regression. This is defined as a return to a state of earlier development [6] or to earlier patterns of adaptation [21]. Refusal, withdrawal and regression have a resistance in common, a rejection of action [28], be it either active and/ or passive. Clinically, an increasingly pervasive negative attitude towards all the activities of daily life can be seen, which can occur in a gradual spectral way from refusal, the one pole, via withdrawal to regression, the other pole. We propose calling this spectrum the RWR (refusal-withdrawal-regression) spectrum. The three manifestations (refusal-withdrawal-regression) can fluctuate in time due to the state of mind of the patient and the context. This state of mind is strongly influenced by the will and the patient's faculty of judgement. Impaired judgement in children and adolescents is frequently linked to trauma, particularly chronic and severe trauma, but can also be due to a major psychiatric disorder. In adults, impaired judgement is most often due to a major psychiatric disorder, such as schizophrenia, an affective disorder or anorexia nervosa. This explains why these three clinically important manifestations of the RWR spectrum are frequently met in the full age range of clinical psychiatry. With PRS, which is diagnosed only in children, refusal and withdrawal are more prominent. In adults, regression is more common.

\section{Diagnosis}

In the diagnostic process, a two-track multidisciplinary diagnostic approach by a paediatrician and a child psychiatrist, as also seen in our case report, is essential from the very beginning, as in the case of a disabling psychiatric disorder, a somatic cause must always be excluded. Regarding Kate, no organic cause of her complaints could be traced.

Thompson and Nunn [24] were the first to introduce diagnostic criteria for PRS (see Table 3). We suggest an adaptation of these criteria (see Table 4). In the past, PRS was often seen as related to eating disorders $[5,10,14,16$, $22]$ and therefore 'clear food refusal and weight loss' was seen as a separate criterion. However, both the literature search and our case report show that refusal can be seen in different domains, including eating. In which domain the refusal is most prominent depends on the individual expression of PRS. We therefore suggest attaching criterion 1, 'clear food refusal and weight loss', to criterion 3 , 'partial or complete refusal in two or more domains'. To underline the severity and disabling character of PRS, we would also like to add an extra criterion: 'The endangered state of the patient requires hospitalization'.

\section{Differential diagnosis}

Pervasive refusal syndrome has many forms of expression, resulting in symptom overlap with other psychiatric

Table 3 Current diagnostic criteria for PRS [24]

Diagnostic criteria for pervasive refusal syndrome

1. Clear food refusal and weight loss

2. Social withdrawal and school refusal

3. Partial or complete refusal in two or more of the following domains: mobilization, speech, attention to personal care

4. Active and angry resistance to acts of help and encouragement

5. No organic condition to account for the severity of the degree of symptoms

6. No other psychiatric disorder that could better account for the symptoms 
Table 4 Adapted diagnostic criteria for PRS

\begin{tabular}{l} 
Diagnostic criteria for pervasive refusal syndrome \\
\hline A. Partial or complete refusal in three or more of the following \\
domains: (1) eating, (2) mobilization, (3) speech, (4) attention to \\
personal care \\
B. Active and angry resistance to acts of help and encouragement \\
C. Social withdrawal and school refusal \\
D. No organic condition accounts for the severity of the degree of \\
symptoms \\
E. No other psychiatric disorder could better account for the \\
symptoms \\
F. The endangered state of the patient requires hospitalization
\end{tabular}

disorders [11]. Table 5 presents an overview of the most common differential diagnoses. None of these diagnoses, however, accounts for the whole variety of symptoms seen in PRS, as described in detail by Bryan Lask (vide infra) [11]. Moreover, the active resistance to any form of help is the distinguishing feature of PRS. Although many of the features of PRS are compatible with a diagnosis of depression, common features of a severe major depressive episode such as psychomotor slowing, a constantly depressed mood and sleep disturbance are uncommon in PRS [11]. Anxiety can be seen in children with PRS, but an anxiety disorder does not account for the whole range of symptoms seen in PRS. Both depression and anxiety can be seen as comorbid to PRS. Food refusal is often seen in PRS, but in general the refusal is neither particularly focused on nor exclusive to food [11]. It is motivated by a desperate need to refuse and not by a desire to lose weight. A diagnosis of eating disorder is therefore not applicable. Selective mutism and school refusal refer to a specific area of functioning, while the refusal seen in PRS is far more pervasive. Chronic fatigue is common in PRS, but by no means the most central feature. Children with chronic

Table 5 Main differential diagnoses of PRS $(n=24)^{\mathrm{a}}$, 1991-2006

\begin{tabular}{lc}
\hline $\begin{array}{l}\text { Main differential } \\
\text { diagnoses }\end{array}$ & $\begin{array}{l}\text { Frequency } \\
\text { (total } n=24)\end{array}$ \\
\hline Depression & $13(54 \%)$ \\
Somatoform disorder & $10(42 \%)$ \\
Anxiety disorder & $7(29 \%)$ \\
Eating disorder & $4(17 \%)$ \\
Chronic fatigue syndrome & $1(4 \%)$ \\
Factitious disorder & $1(4 \%)$ \\
Catatonic disorder/stupor & $1(4 \%)$ \\
Selective mutism & $1(4 \%)$ \\
\hline
\end{tabular}

${ }^{a}$ Twenty-three patients from the literature search +1 patient from the Dutch article [25] fatigue syndrome show very few of the other symptoms of PRS and are frustrated with their ill-health and have a strong wish to recover [11], in contrast to children with PRS.

In our case report, the main differential diagnosis was factitious disorder, in contrast to most of the other published cases (see Table 5). A depressed mood was not found and Kate did not seem anxious at all. She showed situation-specific physical symptoms that had a strong intentional character, which ruled out a somatoform disorder. Her complaints seemed to fluctuate, particularly worsening when parents or medical/nursery staff were present, indicating either a factitious disorder or malingering. A diagnosis of malingering could be excluded because external incentives for her behaviour were not found and were explicitly denied by both Kate and her parents. Factititious disorder was considered but is typically characterised by help-seeking behaviour and not by an active resistance to help, as seen in our patient.

Regression has never been mentioned as a differential diagnosis of PRS in literature. We, however, consider regression as strongly correlated with PRS. In our opinion, and based on the above-mentioned definitions, refusal, withdrawal and regression can be considered different states of the same spectrum, with refusal being the less severe variant and regression the most severe (see "Psychopathological consideration"). A waxing and waning from one state into the other and back again is possible, as is a co-existence of the various states of the RWR spectrum. In PRS, for example, the refusal leads to an increasingly extended social withdrawal. However, as the patient becomes more withdrawn, the refusal remains present. Regression must be considered a more severe and mostly passive state of being with a massive loss of ageadequate psychological functioning. This is partially in contrast to PRS, where active resistance is much more dominant. As regression is mostly seen as a part of an axisI disorder, PRS is considered an entity in its own right. However, the pervasive refusal and active resistance, which are so characteristic of PRS in children, can also be present in adult patients with an axis-I disorder (e.g. severely ill psychiatric patients with anorexia nervosa, a major depressive disorder or a schizophrenic psychosis who show a pervasive refusal and withdrawal from daily life, as well as an active resistance to treatment and who have been involuntary admitted under the mental health act). In line with the aforementioned, the presentations of the RWR spectrum can be seen as an end point in intensity of many untreated - and sometimes even treated-psychiatric disorders.

In contrast to PRS, which is only identified in children, regression is most often seen in adults with an axis-I disorder. It can, however, also affect children. 


\section{Treatment}

Lask et al. [13] stated that 'there is no one specific form of treatment for children as ill as these'. Nunn et al. [19], on the other hand, described a very detailed, specific management approach in the battle against the syndrome. However, no evidence-based treatment is known.

We believe that the treatment must involve a comprehensive multidisciplinary team approach and a structured yet flexible management plan with a clear rationale employed over months to years. Regular multidisciplinary feedback meetings are mandatory in order to minimize splitting.

Because PRS is such a severe condition, hospitalization, ideally in a child and adolescent psychiatric unit, is almost always required. Thompson and Nunn [24] described one treated outpatient. It can be argued that this outpatient treatment was successful. Although Thompson and Nunn described symptom-free periods, there were still periodic relapses of short-lived episodes of depressive symptoms or anorexia. In our opinion, inpatient treatment is therefore necessary (see Table 4).

Treatment must involve tender loving care. The carers must be very patient and sensitive. It takes a long time for the patients to recover, and pressuring them makes their condition worse. It typically takes a few months of treatment before it becomes possible to implement a very gradual rehabilitation programme. Therapeutic enthusiasm in the early stages is almost always counterproductive [11].

The role of the family in the treatment is important yet difficult, since withdrawal of the child from therapy is a major problem. It is important to involve the family in the treatment as it relieves family anxiety and distress. Nevertheless, it is vital to create some distance because overinvolvement of the family may be counterproductive.

Medication appears to play a very limited role in the management of the syndrome, having value in the treatment of comorbid disorders only, for example antidepressants for comorbid depression.

Returning to Kate, treatment consisted of an inpatient multidisciplinary gradual rehabilitation programme, which was characterized by respectful tender loving care and activities just on demand. Parents were involved by means of regular meetings with the family therapist. The treatment goals of these sessions were encouragement, comfort and reduction of possible over-involvement.

Prognosis and outcome

Although the recovery process is painfully slow, most children with PRS fully recover with little residual
Table 6 Treatment characteristics of PRS $(n=24)^{\mathrm{a}}$, 1991-2006

\begin{tabular}{lc}
\hline $\begin{array}{l}\text { Length of time of therapy } \\
\text { in months (mean } \pm \text { SD) }\end{array}$ & $\begin{array}{l}12.8 \pm 11.1 \\
(3 \text { not reported) }\end{array}$ \\
\hline Recovery & $16(67 \%)$ \\
Complete & $6(25 \%)$ \\
Partial & $1(4 \%)$ \\
Not reported & $1(4 \%)$ \\
Symptom-free periods with relapses & \\
Treatment & $22(92 \%)$ \\
Inpatient & $1(4 \%)$ \\
Outpatient & $1(4 \%)$ \\
Not reported & \\
\hline
\end{tabular}

${ }^{a}$ Twenty-three patients from the literature search +1 patient from the Dutch article [25]

pathology [11]. Complete recovery was achieved in 16 $(67 \%)$ of the 24 cases, while partial recovery was seen in six cases $(25 \%)$ (see Table 6). However, the condition of some of the partially recovered patients was still improving at the time of publication. In our case report, full recovery with little residual pathology (fatigue) was seen after a period of 4 months of inpatient treatment ( 1 month at our academic medical psychiatric unit and 3 months at the child psychiatric hospital). This seems a short period of time, because the average duration of therapy is 12.8 months (Table 6). Note, however, that the literature mentions cases of complete recovery after an inpatient treatment of only 2-8 weeks [24]. Concerning Kate, we still have no clue regarding the cause either of her PRS or of her miraculous, spontaneous recovery; but this is also not uncommon.

\section{Conclusion}

In our opinion, PRS, a rare but severe and neglected syndrome with distinct clinical features and a disabling character, should be incorporated into the DSM and ICD classifications and the main textbooks on child and adolescent psychiatry. We propose an adaptation of the current diagnostic criteria and suggest both PRS in children and the well-known concept of regression in adults to be considered as parts of the refusal-withdrawal-regression spectrum.

Acknowledgments We wish to thank Kate and her parents for granting permission to publish their case history; Mrs E.A.F. van Weel, child and adolescent psychiatrist, for initially focusing our attention on PRS; Mr D. Jaspers, professor in English language and literature, and $\mathrm{Mr} \mathrm{S}$. Alford, professional reviser, for critically reviewing and correcting our English; and Ms K. Venrooij, medical secretary, for her editorial work. 
Open Access This article is distributed under the terms of the Creative Commons Attribution Noncommercial License which permits any noncommercial use, distribution, and reproduction in any medium, provided the original author(s) and source are credited.

\section{References}

1. American Psychiatric Association (2000) Diagnostic and statistical manual of mental disorders. DSM-IV-TR. American Psychiatric Association, Washington, DC

2. Anonymous (2001) Pervasive refusal syndrome: a parent's perspective. Clin Child Psychol Psychiatry 6:455-469

3. Bodegard G (2005) Life-threatening loss of function in refugee children: another expression of pervasive refusal syndrome? Clin Child Psychol Psychiatry 10:337-350

4. Bodegard G (2005) Pervasive loss of function in asylum-seeking children in Sweden. Acta Paediatr 94:1706-1707

5. Bryant Waugh R, Lask B (1995) Eating disorders in children. J Child Psychol Psychiatry 36:191-202

6. Dorland WAN, Anderson DM, Novak PD (2003) Dorland's illustrated medical dictionary. Saunders, Philadelphia

7. Edwards H, Done A (2004) Caring for Sophie. A child with pervasive refusal syndrome. Paediatr Nurs 16:39-42

8. Fink M, Carlson GA (1995) ECT and prepubertal children. J Am Acad Child Adolesc Psychiatry 34:1256-1257

9. Graham PJ, Foreman DM (1995) An ethical dilemma in child and adolescent psychiatry. Psychiatric Bull 19:84-86

10. Lask B (2000) Eating disorders in childhood and adolescence. Curr Paediatr 10:254-258

11. Lask B (2004) Pervasive refusal syndrome. Adv Psychiatr Treat 10:153-159

12. Lask B (1996) Pervasive refusal syndrome. ACPP Occas Pap 12:33-35

13. Lask B, Britten C, Kroll L, Magagna J, Tranter M (1991) Children with pervasive refusal. Arch Dis Child 66:866-869

14. Lask B, Bryant Waugh R (1997) Prepubertal eating disorders. In: Garner DM, Garfinkel PE (eds) Handbook of treatment for eating disorders. The Guilford Press, New York, pp 476-483

15. Lewis M (2002) Child and adolescent psychiatry: a comprehensive textbook. Lippincott Williams \& Wilkins, Philadelphia
16. Magagna J (2004) 'I didn't want to die, but I had to': The pervasive refusal syndrome. In: Williams G, Williams P, Desmarais J, Ravenscroft K (eds) Exploring eating disorders in adolescents: the generosity of acceptance. Karnac Books, London, pp 107-138

17. McGowan R, Green J (1998) Pervasive refusal syndrome: a less severe variant with defined aetiology. Clin Child Psychol Psychiatry 3:583-590

18. Nunn KP, Thompson SL (1996) The pervasive refusal syndrome: learned helplessness and hopelessness. Clin Child Psychol Psychiatry 1:121-132

19. Nunn KP, Thompson SL, Moore SG, English M, Burke EA, Byrne N (1998) Managing pervasive refusal syndrome: strategies of hope. Clin Child Psychol Psychiatry 3:229-249

20. Rutter ML, Taylor EA (2002) Child and adolescent psychiatry. Blackwell Science, Oxford

21. Sadock BJ, Sadock VA, Kaplan HI (2004) Diagnosis and psychiatry: examination of the psychiatric patient. In: Kaplan and Sadock's comprehensive textbook of psychiatry. Lippincott Williams \& Wilkins, Philadelphia, pp 857

22. Tate A (2000) Schooling. In: Lask B, Bryant Waugh R (eds) Anorexia nervosa and related eating disorders in childhood and adolescence. Psychology Press, Hove, pp 323-347

23. Taylor S, Dossetor DR, Kilham H, Bernard E (2000) The youngest case of pervasive refusal syndrome? Clin Child Psychol Psychiatry 5:23-29

24. Thompson SL, Nunn KP (1997) The pervasive refusal syndrome: the RAHC experience. Clin Child Psychol Psychiatry 2:145-165

25. van der Stege G (2006) Totaal ontoegankelijk: pervasive refusal syndrome. Kind en Adolescent Praktijk 5:154-159

26. van der Walt M, Baron A (2006) The role of music therapy in the treatment of a girl with pervasive refusal syndrome: exploring approaches to empowerment. Aust J Music Ther 17:35-53

27. Von Folsach LL, Montgomery E (2006) Pervasive refusal syndrome among asylum-seeking children. Clin Child Psychol Psychiatry 11:457-473

28. Waite M, Hawker S, Soanes C (2001) Oxford Dictionary. Thesaurus and Wordpower Guide. Oxford University Press, USA

29. World Health Organisation (2004) ICD-10: international statistical classification of diseases and related health problems: tenth revision. World Health Organization, Geneva 